\title{
First Stereoselective Total Synthesis of Ciryneol C
}

\author{
Ambati Sharada ${ }^{a}$ \\ Lakshmi Srinivasa Rao Kundetia \\ Kallaganti V. S. Ramakrishnab \\ Kommu Nagaiah*a \\ ${ }^{a}$ Centre for Natural Products \& Traditional Knowledge, CSIR-In- \\ dian Institute of Chemical Technology, Hyderabad, 500 007, \\ India \\ nagaiah@iict.res.in \\ ${ }^{b}$ Centre for NMR and SC, CSIR-Indian Institute of Chemical \\ Technology, Hyderabad, 500 007, India
}

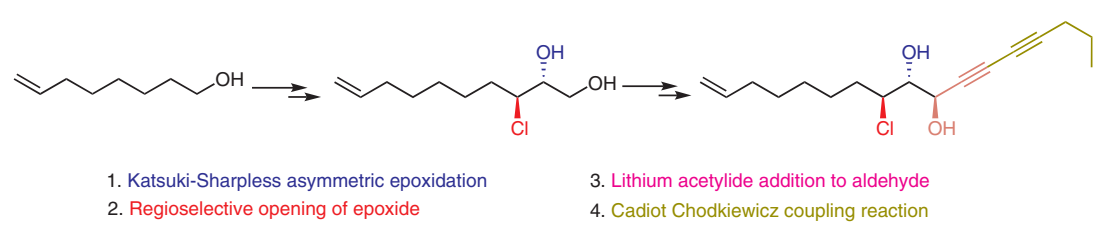

4. Cadiot Chodkiewicz coupling reaction

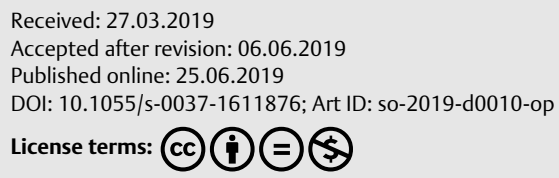

Abstract The acetylene derivative Ciryneol $C$ was isolated from the roots of $C$. japonicum. The asymmetric total synthesis of Ciryneol $C$ was achieved in seven steps, with Horner-Wittig olefination, regioselective epoxide opening, and Cadiot-Chodkiewicz coupling reactions being the key steps.

Key words acetylene, Cadiot-Chodkiewicz coupling, natural products, Sharpless asymmetric epoxidation, total synthesis

Living organisms such as phytoplankton, wood-rotting fungi, and plants produce enzymes such as chloroperoxidase that can use chloride ions to chlorinate organic compounds for use in cell adhesion and in defense processes. ${ }^{1}$ To date, more than 5000 halogenated natural products have been described. Chlorinated acetylene compounds have been found in the secretory canals of Asteraceae species and chlorohydrins in some straight chain acetylenic compounds have been found in Centaurea ruthenica, C. scabiosa and Carthamus tinctorius. $^{2}$

Plant natural products have been used as an alternative to synthetic fungicides because they are considered to be biodegradable and safe for the environment and delicate ecosystems. ${ }^{3}$ Cirsium japonicum is a wild perennial herb used as a herbal remedy to treat uterine bleeding and inflammation and is a widely used in Korea, China, Australia, and Japan. ${ }^{3}$ Extracts of $C$. Japonicum roots are also highly active antifungal agents. Polyacetylenes 1-heptadecene11,13-diyne-8,9,10-triol (1), ciryneol A (2), B (3) and C (4) were isolated from the methanol extract of $C$. Japonicum roots by Takaishi in 1990 (Figure 1 ). ${ }^{4}$ Among these polyacet- ylenes, 1, 2, and 4 inhibited the mycelial growth of plant pathogenic fungi such as Magnaporthe oryzae (rice blast), Rhizoctonia solani (rice sheath blight), Phytophthora infestants (tomato late blight), Puccinia recondita (wheat leaf rust), and Colletotrichum coccodes (red pepper anthracnose) at $500 \mu \mathrm{g} \mathrm{mL} \mathrm{L}^{-1}$ with control values of over $90 \%{ }^{3}$ These polyacetylenes were also highly active against wheat leaf rust at concentrations of $125 \mu \mathrm{g} \mathrm{mL}^{-1}$. Both 2 and 4 inhibited the mycelial growth of Botrytis cinerea but $\mathbf{1}$ had little effect. ${ }^{3}$ Ciryneol C 4 strongly inhibited the mycelial growth of $\mathrm{Fu}$ sarium oxysporum while the other two compounds expressed weak in vitro antifungal activity. ${ }^{3}$ Ciryneol $\mathrm{C} \mathbf{4}$ was highly effective in controlling barley powdery mildew, while the other two compounds were moderately active against this plant disease. ${ }^{3}$

$\mathrm{KB}$ (Keratin-forming tumor cell line) cell growth inhibited by ciryneols and its derivatives was measured in vitro, with concentrations required to give $50 \%$ growth inhibition $\left(\mathrm{ID}_{50}\right)$ of $39.5,10.3,8.6 \mu \mathrm{g} \mathrm{mL}^{-1}$ for $\mathbf{1}, \mathbf{3}$, and $\mathbf{4}$, respectively. ${ }^{4}$ The absolute configuration of ciryneol $\mathrm{C} 4$ was proposed on the basis of CD studies and Mosher's ester analysis. ${ }^{5}$

In a continuation of our synthetic studies on bioactive natural products, we report herein the first total synthesis of ciryneol C 4 from oct-7-en-1-ol (7). Molecules containing a chlorine atom at the stereogenic centre along with an adjacent hydroxyl group are not trivial to synthesize under basic conditions. We designed our synthetic strategy as shown in Scheme 1. Ciryneol C 4 could be obtained from an addition of lithium acetylide and Cadiot-Chodkiewicz coupling of chlorohydrin 5. The synthetic key intermediate chlorohydrin $\mathbf{5}$ could be derived from regioselective ring opening of trans-epoxy alcohol $\mathbf{6}$. The latter could, in turn, be obtained from 7 . 
<smiles>C=CCCCCC[C@H](O)[C@@H](O)[C@H](O)C#CC#CCCC</smiles>

(8S,9R,10S)-heptadeca-1-en-11,13-diyne $-8,9,10$-triol 1<smiles>C=CCCCCC[C@H](OC)[C@@H](O)[C@H](O)C#CC#CCCC</smiles>

Ciryneol B 3<smiles>C=CCCCCCC(OC(=O)O)[C@@H](O)[C@H](O)C#CC#CCCC</smiles>

Ciryneol A 2<smiles>C=CCCCCCC(Cl)[C@H](O)C(O)C#CC#CCCC</smiles>

Ciryneol C 4

Figure 1 Compounds isolated from C. Japonicum

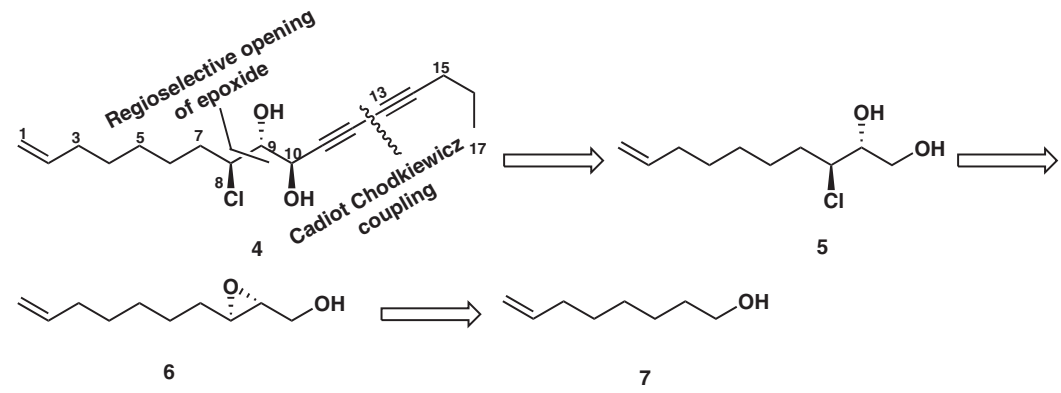

Scheme 1 Retrosynthetic analysis of ciryneol C 4

The key fragment, chlorohydrin $\mathbf{5}$ was synthesized from epoxy alcohol 6, which was, in turn, accessed from $\mathbf{7}$ through oxidation, Horner-Wittig olefination followed by reduction and Sharpless asymmetric epoxidation (Scheme 2). ${ }^{6}$ The epoxy alcohol 6 was protected as its benzoate ester $\left(\mathrm{BzCl}, \mathrm{Et}_{3} \mathrm{~N}, \mathrm{DMAP} \text { and } \mathrm{CH}_{2} \mathrm{Cl}_{2}\right)^{7}$ to give epoxy benzoate $\mathbf{8}$ in $92 \%$ yield. Treatment of epoxy benzoate 8 with the chlorophosphonium reagent generated in situ from $\mathrm{N}$-chlorosuccinamide and triphenylphosphine in toluene at $90{ }^{\circ} \mathrm{C}$ gave vicinal dichloride $\mathbf{9}$ in good yield. ${ }^{8}$ The latter was then treated with potassium carbonate in methanol ${ }^{7}$ to give alcohol 10 exclusively, but did not furnish chloroepoxide $\mathbf{1 1}$.

Treating alcohol 10 with $\mathrm{NaH}$ in THF at $0{ }^{\circ} \mathrm{C}$ led to no reaction, and the starting material decomposed on heating to reflux. When the reaction was repeated with potassium carbonate in methanol at reflux, epoxyether $\mathbf{1 2}$ was obtained in $85 \%$ yield instead of chloroepoxide 11; the same outcome was observed with $\mathrm{Cs}_{2} \mathrm{CO}_{3}$ in ethanol at room temperature, giving epoxyether $\mathbf{1 3}$ in $86 \%$ yield (Scheme 3 ).

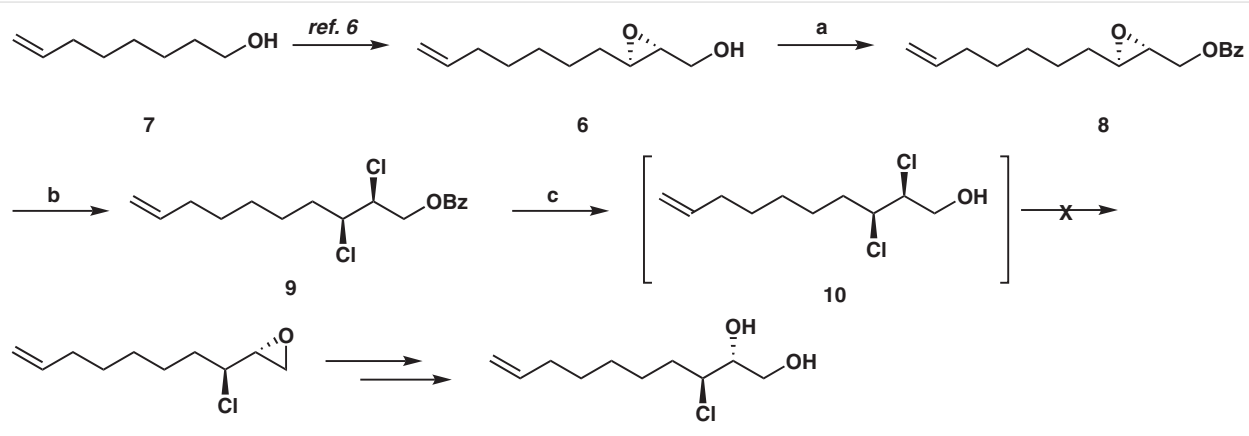

11

5

Scheme 2 Reagents and conditions: (a) Et ${ }_{3} \mathrm{~N}$, DMAP, $\mathrm{C}_{6} \mathrm{H}_{5} \mathrm{COCl}, \mathrm{CH}_{2} \mathrm{Cl}_{2}, 0{ }^{\circ} \mathrm{C}$ to r.t., $2 \mathrm{~h}, 92 \%$ yield. (b) Triphenylphosphine, NCS, toluene, $90{ }^{\circ} \mathrm{C}, 1 \mathrm{~h}, 88 \%$ yield. (c) $\mathrm{K}_{2} \mathrm{CO}_{3}$, methanol, $0{ }^{\circ} \mathrm{C}$ to r.t., $2 \mathrm{~h}, 89 \%$ yield. 

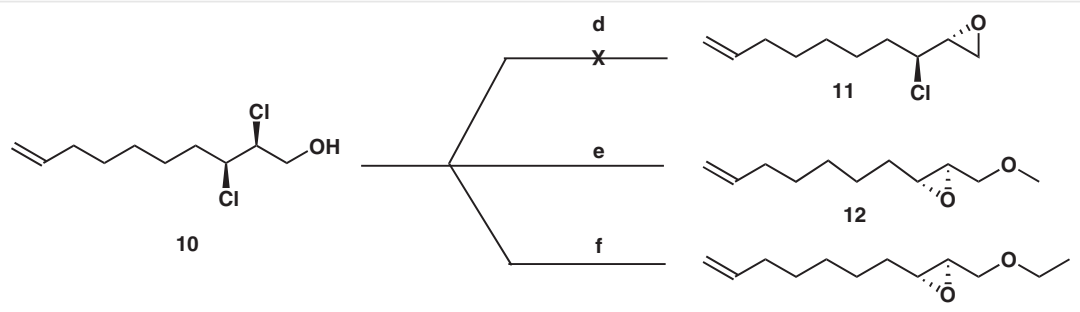

13

Scheme 3 Reagents and conditions: (d) $\mathrm{NaH}, \mathrm{THF}, 66^{\circ} \mathrm{C}, 1$ h. (e) $\mathrm{K}_{2} \mathrm{CO}_{3}, \mathrm{CH}_{3} \mathrm{OH}, 65^{\circ} \mathrm{C}, 2 \mathrm{~h}, 85 \%$ yield. (f) $\mathrm{Cs}_{2} \mathrm{CO}_{3}, \mathrm{C}_{2} \mathrm{H}_{5} \mathrm{OH}, 0{ }^{\circ} \mathrm{C}, 1 \mathrm{~h}, 86 \%$ yield.

To overcome the above problem, an alternative route was utilized for the synthesis of chlorohydrin $\mathbf{5}$, involving regioselective ring opening of epoxy alcohol $\mathbf{6}$ with $\mathrm{CeCl}_{3}$ in monoglyme to furnish the required chlorohydrin $\mathbf{5}$ in 84\% yield (Scheme 4). ${ }^{9}$ Both hydroxy groups of chlorohydrin $\mathbf{5}$ were then protected as TBS ethers by treatment with TBS chloride and imidazole in DMF to afford 14 in $90 \%$ yield. ${ }^{10}$ The di-TBS ether $\mathbf{1 4}$ underwent subsequent regioselective controlled desilylation in the presence of camphorsulfonic acid in methanol at $0{ }^{\circ} \mathrm{C}$ to yield the corresponding primary alcohol 15 in $85 \%$ yield. ${ }^{11}$ The primary alcohol 15, on treatment with 2-iodoxybenzoic acid (IBX), afforded the corresponding aldehyde $16^{10}$ in $88 \%$ yield, and addition of the organolithium reagent derived from trimethylsilylacetylene to aldehyde $\mathbf{1 6}$ afforded a mixture of diastereomers $\mathbf{1 7} \mathbf{a}$ and $\mathbf{1 7 b}^{12}$ (9:2 ratio, confirmed by ${ }^{1} \mathrm{H}$ NMR analysis). Attempted removal of the trimethylsilyl group in $\mathbf{1 7} \mathbf{a}$ and $\mathbf{1 7} \mathbf{b}$ under basic conditions $\left(\mathrm{K}_{2} \mathrm{CO}_{3} \text { in methanol }\right)^{13}$ led to an unidenti- fied product. Subsequently, we tried to remove both silyl groups with tetrabutylammonium fluoride (TBAF) in THF, ${ }^{14}$ but this furnished epoxy alcohols 20a and 20b instead of diols 19a and 19b (Scheme 4).

To avoid this issue, the resulting alcohols $\mathbf{1 7} \mathbf{a}$ and $\mathbf{1 7 b}$ were protected using TBSCl, imidazole and DMAP in $\mathrm{DMF}^{15}$ to give fully protected alkyne 21a and 21b in 92\% yield (Scheme 5); deprotection of the acetylenic function was then successfully achieved $\left(\mathrm{K}_{2} \mathrm{CO}_{3}\right.$ in $\left.\mathrm{CH}_{3} \mathrm{OH}, 91 \%\right),{ }^{13}$ followed by deprotection of the di- TBS ether using PTSA (20 mol\%) in methanol to give diols 19 a and 19b in $89 \%$ yield. The diastereomers were separated by column chromatography. Alternatively, alcohols $\mathbf{1 7} \mathbf{a}$ and $\mathbf{1 7 b}$ could be reacted with TBAF (1 M in THF) and acetic acid (1 M in THF) at $0{ }^{\circ} \mathrm{C}$ to furnish diols $\mathbf{1 9 a}$ and $\mathbf{1 9 b}$ in $74 \%$ yield.

The target molecule ciryneol C $\mathbf{4}$ was obtained under Cadiot-Chodkiewicz ${ }^{16}$ coupling conditions between diol 19a and 1-iodopent-1-yne.
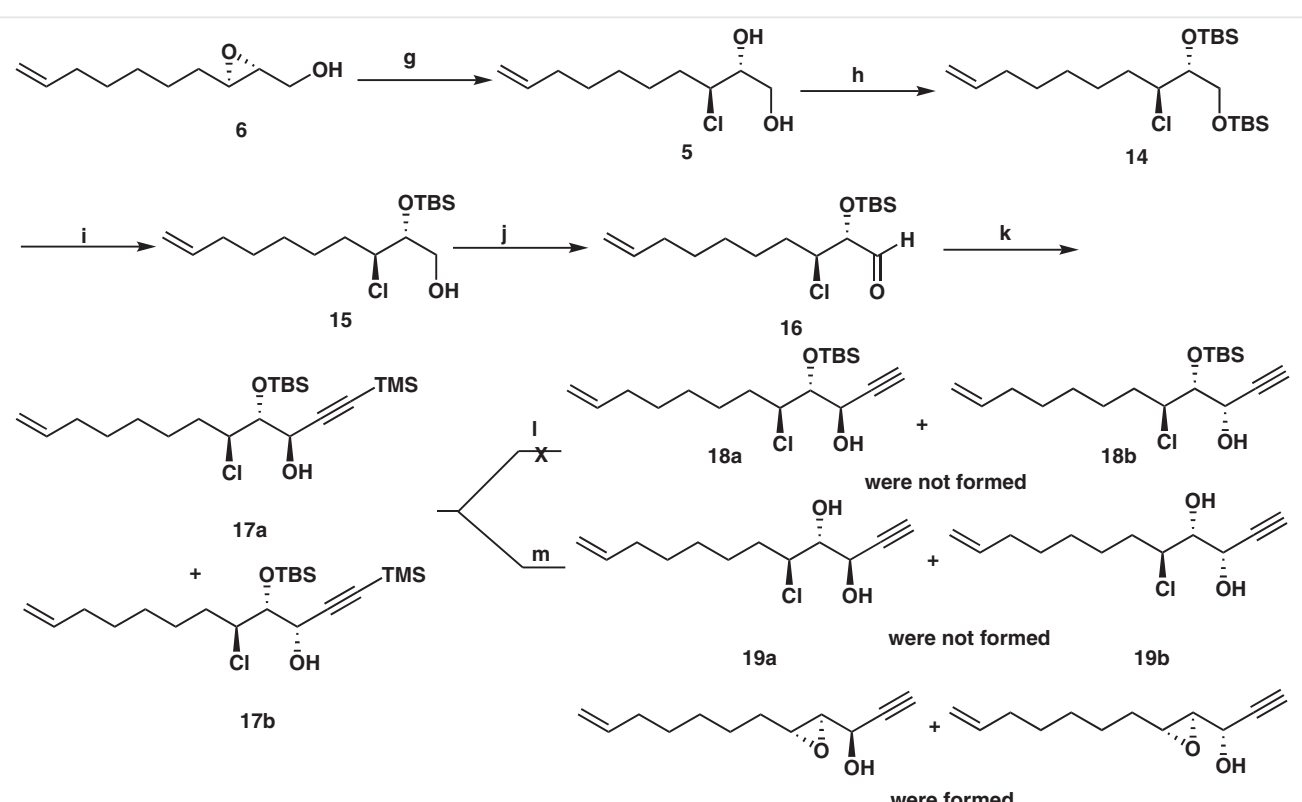

$20 \mathrm{a}$

Scheme 4 Reagents and conditions: (g) $\mathrm{CeCl}_{3}$, monoglyme, r.t., $12 \mathrm{~h}, 84 \%$ yield. (h) TBSCl, imidazole, DMAP, DMF, $0{ }^{\circ} \mathrm{C}$ to r.t., $24 \mathrm{~h}, 90 \%$ yield. (i) $\mathrm{CSA}$, $\mathrm{CH}_{2} \mathrm{Cl}_{2}$, methanol $(1: 1),-10{ }^{\circ} \mathrm{C}, 2 \mathrm{~h}, 85 \%$ yield. (j) IBX, DMSO, $\mathrm{CH}_{2} \mathrm{Cl}_{2}, 0{ }^{\circ} \mathrm{C}$ to r.t., $4 \mathrm{~h}, 88 \%$ yield. (k) (i) $n$-BuLi, TMS acetylene, THF, $-78{ }^{\circ} \mathrm{C}($ ii) $16, \mathrm{THF}$, $-78{ }^{\circ} \mathrm{C}, 1 \mathrm{~h}, 87 \%$ yield. (I) $\mathrm{K}_{2} \mathrm{CO}_{3}, \mathrm{CH}_{3} \mathrm{OH}, 0{ }^{\circ} \mathrm{C}, 2 \mathrm{~h}$. (m) TBAF, THF, $0{ }^{\circ} \mathrm{C}, 1 \mathrm{~h}, 81 \%$ yield. 


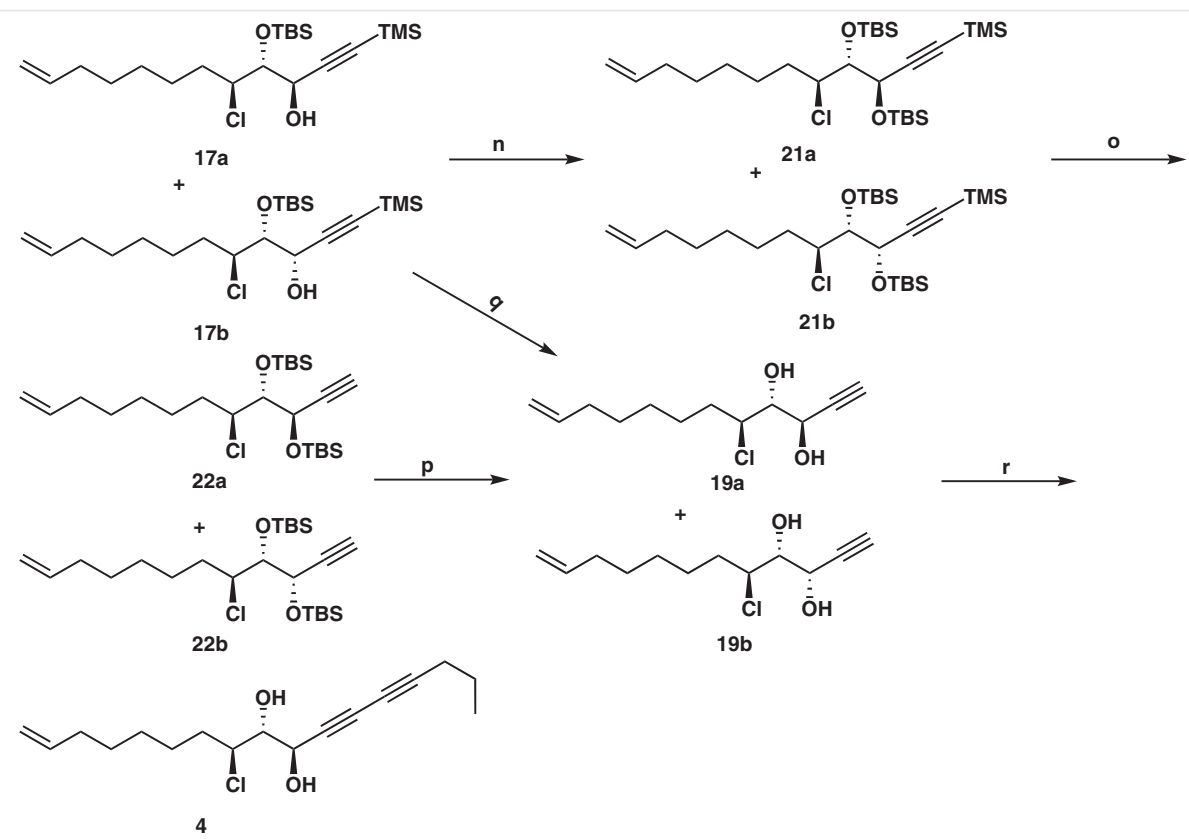

Scheme 5 Reagents and conditions: (n) TBSCl, imidazole, DMAP, DMF, $0{ }^{\circ} \mathrm{C}$ to r.t., $24 \mathrm{~h}, 92 \%$ yield. (o) $\mathrm{K}_{2} \mathrm{CO}_{3}, \mathrm{CH}_{3} \mathrm{OH}, 0{ }^{\circ} \mathrm{C}$ to r.t., $1 \mathrm{~h}, 91 \%$ yield. (p) PTSA, $\mathrm{CH}_{3} \mathrm{OH}, 0{ }^{\circ} \mathrm{C}$ to r.t., $2 \mathrm{~h}, 89 \%$ yield. (q) TBAF, acetic acid, THF, $0{ }^{\circ} \mathrm{C}, 1 \mathrm{~h}, 74 \%$. (r) $\mathrm{CuCl}, \mathrm{NH}_{2} \mathrm{OH} \cdot \mathrm{HCl}, \mathrm{n}$-BuNH $\mathrm{H}_{2}, 1$-iodopent-1-yne, diethyl ether, $0{ }^{\circ} \mathrm{C}, 1 \mathrm{~h}$, $81 \%$ yield.

All commercially available chemicals and reagents were used without further purification unless otherwise indicated. All reactions are carried out under $\mathrm{N}_{2}$ atmosphere. Thin-layer chromatography was performed using commercially available silica plates coated with fluorescent indicator and visualization was effected at $254 \mathrm{~nm}$. Column chromatography was carried out using Merck 60-120 mesh silica gel. NMR spectra were recorded in $\mathrm{CDCl}_{3}$ with Bruker 300, 400, and 500 $\mathrm{MHz}$ spectrometers. Chemical shifts are reported in parts per million $(\delta)$ relative to TMS $(0.00 \mathrm{ppm})$ for ${ }^{1} \mathrm{H}$ NMR and $\mathrm{CDCl}_{3}(77.00 \mathrm{ppm})$ for ${ }^{13} \mathrm{C}$ NMR. Specific rotations were measured with a Digipol $781 \mathrm{M} 6 \mathrm{U}$ Automatic Polarimeter. IR spectra were measured with a Jasco FT/IR410 spectrometer. HRMS were recorded with an Agilent 6545 Q-TOF LCMS, source ESI. Compounds $\mathbf{6}$ and $\mathbf{7}$ were prepared according to the reported methods. ${ }^{6}$

\section{((2R,3R)-3-(Hept-6-enyl)oxiran-2-yl)methylbenzoate (8)}

To a stirred solution of epoxide $\mathbf{6}(1 \mathrm{~g}, 5.88 \mathrm{mmol})$ in $\mathrm{CH}_{2} \mathrm{Cl}_{2}(10 \mathrm{~mL})$ at $0{ }^{\circ} \mathrm{C}$ were sequentially added $\mathrm{Et}_{3} \mathrm{~N}(1.0 \mathrm{~mL}, 7.05 \mathrm{mmol})$, DMAP (86 $\mathrm{mg}, 705 \mu \mathrm{mol}$ ) and benzoyl chloride $(751 \mu \mathrm{L}, 6.46 \mathrm{mmol})$. Stirring was continued for $2 \mathrm{~h}$ and a saturated solution of $\mathrm{NH}_{4} \mathrm{Cl}(3 \mathrm{~mL})$ was added at $0{ }^{\circ} \mathrm{C}$. The reaction mixture was extracted with $\mathrm{CH}_{2} \mathrm{Cl}_{2}(3 \times 20 \mathrm{~mL})$ and the combined organic phases were dried over $\mathrm{Na}_{2} \mathrm{SO}_{4}$, filtered, and concentrated. Purification of the residue by silica column chromatography (hexane/EtOAc, 19:1) gave epoxy benzoate 8.

Yield: $1.48 \mathrm{~g}$ (92\%); colorless liquid; $[\alpha]_{D}{ }^{20}+23.6\left(c 2.0, \mathrm{CHCl}_{3}\right)$.

IR (neat): 3069, 2928, 1720, 1640, 1451, 1111, 907, $710 \mathrm{~cm}^{-1}$.

${ }^{1} \mathrm{H} \mathrm{NMR}\left(300 \mathrm{MHz}, \mathrm{CDCl}_{3}\right): \delta=8.07(\mathrm{dd}, J=1.5,8.4 \mathrm{~Hz}, 2 \mathrm{H}), 7.58(\mathrm{tt}$, $J=1.3,8.6 \mathrm{~Hz}, 1 \mathrm{H}), 7.45(\mathrm{tt}, J=1.5,7.3 \mathrm{~Hz}, 2 \mathrm{H}), 5.88-5.72(\mathrm{~m}, 1 \mathrm{H})$, $5.05-4.89(\mathrm{~m}, 2 \mathrm{H}), 4.60(\mathrm{dd}, J=3.2,12.0 \mathrm{~Hz}, 1 \mathrm{H}), 4.20(\mathrm{dd}, J=6.0$, $12.0 \mathrm{~Hz}, 1 \mathrm{H}), 3.14-3.06(\mathrm{~m}, 1 \mathrm{H}), 2.94(\mathrm{td}, J=2.2,5.4 \mathrm{~Hz}, 1 \mathrm{H}), 2.10-$ 1.98 (m, $2 \mathrm{H}), 1.66-1.54$ (m, $2 \mathrm{H}), 1.54-1.28$ (m, $6 \mathrm{H})$.
${ }^{13} \mathrm{C}$ NMR $\left(100 \mathrm{MHz}, \mathrm{CDCl}_{3}\right): \delta=166.2,138.8,133.1,129.7$ (3C), 128.3 (2C), 114.3, 65.2, 56.6, 55.3, 33.5, 31.4, 28.7, 28.7, 25.6.

HRMS (ESI): $m / z[M+H]^{+}$calcd for $\mathrm{C}_{17} \mathrm{H}_{23} \mathrm{O}_{3}{ }^{+}:$:275.1642; found: 275.1639 .

\section{(2S,3S)-2,3-Dichlorodec-9-enyl Benzoate (9)}

To a stirred solution of epoxy benzoate $8(1.0 \mathrm{~g}, 3.64 \mathrm{mmol})$ in toluene $(45 \mathrm{~mL})$ at r.t. were added $\mathrm{Ph}_{3} \mathrm{P}(2.86 \mathrm{~g}, 10.9 \mathrm{mmol})$ and NCS (1.45 g, $10.9 \mathrm{mmol}$ ). The mixture was heated at $90{ }^{\circ} \mathrm{C}$ for $1 \mathrm{~h}$ and the mixture was cooled to $0{ }^{\circ} \mathrm{C}$ and treated with sat. aq. $\mathrm{Na}_{2} \mathrm{~S}_{2} \mathrm{O}_{3}(20 \mathrm{~mL})$ and sat. aq. $\mathrm{NaHCO}_{3}(30 \mathrm{~mL})$. The reaction mixture was extracted with EtOAc $(3 \times 20 \mathrm{~mL})$, the combined organic phases were dried over $\mathrm{Na}_{2} \mathrm{SO}_{4}$, filtered, and concentrated. The crude product was purified by silica column chromatography (hexane/EtOAc, 98:2) to give dichloride $\mathbf{9}$.

Yield: $1.05 \mathrm{~g}$ (88\%); colorless oil; $[\alpha]_{\mathrm{D}}{ }^{20}-34.2\left(\mathrm{c} 2.0, \mathrm{CHCl}_{3}\right)$.

IR (neat): 3073, 2925, 1725, 1641, 1452, 1268, 911, $710 \mathrm{~cm}^{-1}$.

${ }^{1} \mathrm{H}$ NMR $\left(500 \mathrm{MHz}, \mathrm{CDCl}_{3}\right.$ ): $\delta=8.05$ (dd, $\left.J=1.2,8.2 \mathrm{~Hz}, 2 \mathrm{H}\right), 7.59(\mathrm{tt}$, $J=1.3,8.8 \mathrm{~Hz}, 1 \mathrm{H}), 7.46(\mathrm{tt}, J=1.5,8.0 \mathrm{~Hz}, 2 \mathrm{H}), 5.84-5.74(\mathrm{~m}, 1 \mathrm{H})$, 5.02-4.97 (m, 1 H), 4.96-4.92 (m, $1 \mathrm{H}), 4.64(\mathrm{~d}, J=2.7 \mathrm{~Hz}, 1 \mathrm{H}), 4.62$ $(\mathrm{d}, J=2.8 \mathrm{~Hz}, 1 \mathrm{H}), 4.41(\mathrm{td}, J=2.4,6.7 \mathrm{~Hz}, 1 \mathrm{H}), 4.25-4.21(\mathrm{~m}, 1 \mathrm{H})$, 2.08-2.02 (m, 2 H), 1.96-1.89 (m, 2 H), 1.63-1.53 (m, 1 H), 1.48-1.30 $(\mathrm{m}, 5 \mathrm{H})$.

${ }^{13} \mathrm{C}$ NMR $\left(100 \mathrm{MHz}, \mathrm{CDCl}_{3}\right): \delta=165.8,138.6,133.9,129.7,129.3$, 128.4, 114.4, 65.5, 61.8, 60.9, 35.0, 33.5, 28.5, 28.3, 26.3.

HRMS (ESI): $m / z[M+H]^{+}$calcd for $\mathrm{C}_{17} \mathrm{H}_{23} \mathrm{Cl}_{2} \mathrm{O}_{2}{ }^{+}: 329.1070$; found: 329.1063 .

\section{(2S,3S)-2,3-Dichlorodec-9-en-1-ol (10)}

Potassium carbonate ( $84 \mathrm{mg}, 609 \mu \mathrm{mol}$ ) was added to a stirred solution of benzoate $\mathbf{9}(100 \mathrm{mg}, 304 \mu \mathrm{mol})$ in $\mathrm{MeOH}(2 \mathrm{~mL})$ at $0{ }^{\circ} \mathrm{C}$ and the mixture allowed to stir for $2 \mathrm{~h}$ before quenching with $\mathrm{NH}_{4} \mathrm{Cl}(2 \mathrm{~mL})$. 
The reaction mixture was concentrated and extracted with EtOAc $(3 \times 5 \mathrm{~mL})$, the combined organic phases were dried over $\mathrm{Na}_{2} \mathrm{SO}_{4}$, filtered and concentrated. The residue was purified by silica column chromatography (hexane/EtOAc, 9:1) to give alcohol $\mathbf{1 0 .}$

Yield: $60.7 \mathrm{mg}$ (89\%); colorless liquid; $[\alpha]_{\mathrm{D}}{ }^{20}-62.2$ (c 2.0, $\left.\mathrm{CHCl}_{3}\right)$.

IR (neat): 3396, 3077, 2924, 1641, 1461, 1051, $901 \mathrm{~cm}^{-1}$.

${ }^{1} \mathrm{H} \mathrm{NMR}\left(500 \mathrm{MHz}, \mathrm{CDCl}_{3}\right): \delta=5.88-5.71(\mathrm{~m}, 1 \mathrm{H}), 5.06-4.90(\mathrm{~m}, 2 \mathrm{H})$, 4.28-4.13 (m, 2 H), 4.01-3.81 (m, 2 H), 2.12-1.82 (m, 5 H), 1.68-1.18 $(\mathrm{m}, 5 \mathrm{H})$.

${ }^{13} \mathrm{C}$ NMR $\left(125 \mathrm{MHz}, \mathrm{CDCl}_{3}\right): \delta=138.7,114.4,65.3,64.4,61.9,35.1$, 33.5, 28.6, 28.3, 26.3.

HRMS (ESI): $m / z$ [M + Na] $]^{+}$calcd for $\mathrm{C}_{10} \mathrm{H}_{18} \mathrm{Cl}_{2} \mathrm{ONa}^{+}$: 247.0627; found: 247.0636 .

\section{(2R,3R)-2-(Hept-6-enyl)-3-(methoxymethyl)oxirane (12)}

Potassium carbonate $(123 \mathrm{mg}, 892 \mu \mathrm{mol}$ ) was added to a stirred solution of alcohol $10(100 \mathrm{mg}, 446 \mu \mathrm{mol})$ in $\mathrm{MeOH}(2 \mathrm{~mL})$ at $0{ }^{\circ} \mathrm{C}$, the mixture allowed to stir at $65{ }^{\circ} \mathrm{C}$ for $2 \mathrm{~h}$ and then quenched with $\mathrm{NH}_{4} \mathrm{Cl}$ $(20 \mathrm{~mL})$. The reaction mixture was concentrated and extracted with EtOAc $(3 \times 5 \mathrm{~mL})$ and the combined organic phases were dried over $\mathrm{Na}_{2} \mathrm{SO}_{4}$, filtered and concentrated. The residue was purified by silica column chromatography (hexane/EtOAc, 97:3) to give epoxyether 12. Yield: $69.8 \mathrm{mg}$ (85\%); colorless liquid; $[\alpha]_{\mathrm{D}}^{20}-1.2$ (c 1.0, $\mathrm{CHCl}_{3}$ ).

IR (neat): 3070, 2924, 1685, 1453, 1127, $933 \mathrm{~cm}^{-1}$.

${ }^{1} \mathrm{H} \mathrm{NMR}\left(300 \mathrm{MHz}, \mathrm{CDCl}_{3}\right): \delta=5.89-5.71(\mathrm{~m}, 1 \mathrm{H}), 5.06-4.89(\mathrm{~m}, 2 \mathrm{H})$, $3.64(\mathrm{dd}, J=3.0,11.2 \mathrm{~Hz}, 1 \mathrm{H}), 3.43-3.34(\mathrm{~m}, 1 \mathrm{H}), 3.39(\mathrm{~s}, 3 \mathrm{H}), 2.93-$ $2.87(\mathrm{~m}, 1 \mathrm{H}), 2.82(\mathrm{td}, J=2.2,5.5 \mathrm{~Hz}, 1 \mathrm{H}), 2.11-2.00(\mathrm{~m}, 2 \mathrm{H}), 1.65-$ $1.28(\mathrm{~m}, 8 \mathrm{H})$.

${ }^{13} \mathrm{C}$ NMR $\left(125 \mathrm{MHz}, \mathrm{CDCl}_{3}\right): \delta=138.9,114.3,72.7,59.1,56.7,55.9$, 33.6, 31.6, 28.8, 28.7, 25.7.

HRMS (ESI): $m / z$ [M + Na] calcd for $\mathrm{C}_{11} \mathrm{H}_{20} \mathrm{O}_{2} \mathrm{Na}^{+}:$207.1356; found: 207.1369.

\section{(2R,3R)-2-(Ethoxymethyl)-3-(hept-6-enyl)oxirane (13)}

Cesium carbonate ( $174 \mathrm{mg}, 535 \mu \mathrm{mol}$ ) was added to a stirred solution of alcohol $10(100 \mathrm{mg}, 446 \mu \mathrm{mol})$ in $\mathrm{EtOH}(2 \mathrm{~mL})$ at $0{ }^{\circ} \mathrm{C}$ and the mixture allowed to stir for $1 \mathrm{~h}$ before quenching with $\mathrm{NH}_{4} \mathrm{Cl}(20 \mathrm{~mL})$. The reaction mixture was concentrated to remove $\mathrm{EtOH}$ and extracted with EtOAc $(3 \times 5 \mathrm{~mL})$. The combined organic phases were dried over $\mathrm{Na}_{2} \mathrm{SO}_{4}$, filtered, and concentrated. The residue was purified by silica column chromatography (hexane/EtOAc, 97:3) to give epoxyether 13. Yield: $76 \mathrm{mg}$ (86\%); colorless liquid; $[\alpha]_{\mathrm{D}}{ }^{20}-0.9$ (c 1.0, $\mathrm{CHCl}_{3}$ ).

IR (neat): 3076, 2925, 1640, 1461, 1116, $909 \mathrm{~cm}^{-1}$.

${ }^{1} \mathrm{H}$ NMR $\left(500 \mathrm{MHz}, \mathrm{CDCl}_{3}\right): \delta=5.85-5.76(\mathrm{~m}, 1 \mathrm{H}), 5.00(\mathrm{dd}, J=1.5$, $17.0 \mathrm{~Hz}, 1 \mathrm{H}$ ), 4.94 (dd, $J=1.5,10.8 \mathrm{~Hz}, 1 \mathrm{H}), 3.66$ (dd, $J=3.3,11.4 \mathrm{~Hz}$, $1 \mathrm{H}), 3.60-3.49(\mathrm{~m}, 2 \mathrm{H}), 3.42(\mathrm{dd}, J=5.6,11.4 \mathrm{~Hz}, 1 \mathrm{H}), 2.92-2.88(\mathrm{~m}$, $1 \mathrm{H}), 2.81(\mathrm{td}, J=2.1,5.6 \mathrm{~Hz}, 1 \mathrm{H}), 2.08-2.02(\mathrm{~m}, 2 \mathrm{H}), 1.65-1.31(\mathrm{~m}$, $8 \mathrm{H}), 1.21(\mathrm{t}, J=7.0 \mathrm{~Hz}, 3 \mathrm{H})$.

${ }^{13} \mathrm{C}$ NMR $\left(125 \mathrm{MHz}, \mathrm{CDCl}_{3}\right): \delta=138.9,114.3,70.8,66.7,56.9,56.1$, 33.6, 31.6, 28.8, 28.7, 25.7, 15.1 .

HRMS (ESI): $m / z[M+H]^{+}$calcd for $\mathrm{C}_{12} \mathrm{H}_{23} \mathrm{O}_{2}$ : 199.1693; found: 199.1694 .

\section{(2R,3S)-3-Chlorodec-9-ene-1,2-diol (5)}

To a stirred solution of epoxy alcohol 6 (3 g, $17.6 \mathrm{mmol})$ in monoglyme $(30 \mathrm{~mL})$ at r.t. was added cerium chloride $(2.53 \mathrm{~g}, 8.82 \mathrm{mmol})$ and stirring was continued for $12 \mathrm{~h}$. The reaction mixture was quenched with sat. aq. $\mathrm{NaHCO}_{3}$ at $0{ }^{\circ} \mathrm{C}$ and extracted with diethyl ether $(3 \times 15 \mathrm{~mL})$. The combined organic phases were washed with brine, dried over $\mathrm{Na}_{2} \mathrm{SO}_{4}$, filtered, and the solvent was removed under reduced pressure. The residue was purified by silica column chromatography (hexane/EtOAc, 85:15) to give chlorohydrin 5.

Yield: $3.0 \mathrm{~g}$ (84\%); colorless liquid; $[\alpha]_{\mathrm{D}}^{20}-26.0$ (c 3.0, $\mathrm{CHCl}_{3}$ ).

IR (neat): 3358, 3078, 2926, 1640, 1435, 1054, 909, $688 \mathrm{~cm}^{-1}$.

${ }^{1} \mathrm{H}$ NMR $\left(400 \mathrm{MHz}, \mathrm{CDCl}_{3}\right): \delta=5.86-5.75(\mathrm{~m}, 1 \mathrm{H}), 5.04-4.97(\mathrm{~m}, 1 \mathrm{H})$, 4.97-4.92 (m, $1 \mathrm{H}), 3.99-3.92(\mathrm{~m}, 1 \mathrm{H}), 3.86-3.73(\mathrm{~m}, 3 \mathrm{H}), 3.04-2.78$ (brs, $1 \mathrm{H}$ ), 2.57-2.23 (brs, $1 \mathrm{H}), 2.10-2.02$ (m, $2 \mathrm{H}), 1.95-1.85$ (m, $1 \mathrm{H}$ ), 1.76-1.55 (m, $2 \mathrm{H}), 1.48-1.24(\mathrm{~m}, 5 \mathrm{H})$.

${ }^{13} \mathrm{C}$ NMR $\left(100 \mathrm{MHz}, \mathrm{CDCl}_{3}\right): \delta=138.8,114.3,74.6,63.8,63.4,33.5$, 33.5, 28.6, 28.4, 26.1.

HRMS (ESI): $m / z$ [M + Na $]^{+}$calcd for $\mathrm{C}_{10} \mathrm{H}_{19} \mathrm{ClO}_{2} \mathrm{Na}$ : 229.0966; found: 229.0969 .

\section{(R)-5-((S)-1-Chlorooct-7-enyl)-2,2,3,3,8,8,9,9-octamethyl-4,7-di- oxa-3,8-disiladecane (14)}

To a stirred solution of diol 5 (1.30 g, $6.31 \mathrm{mmol})$ in DMF $(10 \mathrm{~mL})$ were added imidazole ( $1.28 \mathrm{~g}, 18.9 \mathrm{mmol}), \mathrm{TBSCl}(2.37 \mathrm{~g}, 15.7 \mathrm{mmol})$, and DMAP (178 mg, $0.63 \mathrm{mmol}$ ) at $0{ }^{\circ} \mathrm{C}$ and the mixture was stirred at r.t. for $24 \mathrm{~h}$. The reaction mixture was quenched by the addition of cold water $(20 \mathrm{~mL})$ and extracted with EtOAc $(3 \times 30 \mathrm{~mL})$. The combined organic phases were dried over $\mathrm{Na}_{2} \mathrm{SO}_{4}$, filtered and the solvent was removed under reduced pressure. The residue was purified by silica column chromatography (hexane, 100\%) to afford bis-silyl ether 14.

Yield: $2.46 \mathrm{~g}$ (90\%); colorless oil; $[\alpha]_{\mathrm{D}}^{20}-15.6$ ( c $0.9, \mathrm{CHCl}_{3}$ ).

IR (neat): 2952, 2928, 1641, 1465, 1116, 909, $668 \mathrm{~cm}^{-1}$.

${ }^{1} \mathrm{H}$ NMR $\left(400 \mathrm{MHz}, \mathrm{CDCl}_{3}\right): \delta=5.86-5.75(\mathrm{~m}, 1 \mathrm{H}), 5.03-4.98(\mathrm{~m}, 1 \mathrm{H})$, 4.96-4.91 (m, $1 \mathrm{H}), 4.09-4.03(\mathrm{~m}, 1 \mathrm{H}), 3.89-3.83(\mathrm{~m}, 1 \mathrm{H}), 3.66-3.56$ (m, $2 \mathrm{H}), 2.10-2.02(\mathrm{~m}, 2 \mathrm{H}), 1.85-1.74(\mathrm{~m}, 1 \mathrm{H}), 1.72-1.54(\mathrm{~m}, 2 \mathrm{H})$, 1.46-1.25 (m, $5 \mathrm{H}), 0.90(\mathrm{~s}, 18 \mathrm{H}), 0.12(\mathrm{~s}, 3 \mathrm{H}), 0.09$ (s, $3 \mathrm{H}), 0.06$ (s, $3 \mathrm{H}), 0.05$ (s, $3 \mathrm{H})$.

${ }^{13} \mathrm{C}$ NMR $\left(100 \mathrm{MHz}, \mathrm{CDCl}_{3}\right): \delta=138.9,114.2,76.8,64.6,64.1,33.7$, 31.7, 28.7, 28.6, 26.4, 25.9, 25.8, 18.2, 18.1, -4.3, -4.6, -5.4, -5.4.

HRMS (ESI): $m / z[\mathrm{M}+\mathrm{H}]^{+}$calcd for $\mathrm{C}_{22} \mathrm{H}_{48} \mathrm{ClO}_{2} \mathrm{Si}_{2}{ }^{+}$: 435.2876; found: 435.2885 .

\section{(2R,3S)-2-(tert-Butyldimethylsilyloxy)-3-chlorodec-9-en-1-ol (15)} To a stirred solution of the di-TBS ether $\mathbf{1 4}(1.30 \mathrm{~g}, 2.99 \mathrm{mmol})$ in $\mathrm{CH}_{2^{-}}$ $\mathrm{Cl}_{2}(5 \mathrm{~mL})$ and $\mathrm{MeOH}(5 \mathrm{~mL})$ at $-10{ }^{\circ} \mathrm{C}, \mathrm{CSA}(70 \mathrm{mg}, 300 \mu \mathrm{mol})$ was added and stirring was continued for $2 \mathrm{~h}$ at the same temperature. The reaction mixture was quenched with solid $\mathrm{NaHCO}_{3}(52 \mathrm{mg}, 620$ $\mu \mathrm{mol})$, filtered, extracted with $\mathrm{CH}_{2} \mathrm{Cl}_{2}(3 \times 20 \mathrm{~mL})$, and the combined extracts were dried over $\mathrm{Na}_{2} \mathrm{SO}_{4}$. Filtration, concentration under reduced pressure and purification of the residue by silica column chromatography (hexane/EtOAc, 95:5) gave alcohol 15.

Yield: $814 \mathrm{mg}$ (85\%); colorless oil; $[\alpha]_{\mathrm{D}}{ }^{20}-18.2\left(\mathrm{c} 0.7, \mathrm{CHCl}_{3}\right)$.

IR (neat): 3422, 3077, 2928, 1641, 1464, 1110, 909, $682 \mathrm{~cm}^{-1}$.

${ }^{1} \mathrm{H} \mathrm{NMR}\left(400 \mathrm{MHz}, \mathrm{CDCl}_{3}\right): \delta=5.87-5.75(\mathrm{~m}, 1 \mathrm{H}), 5.03-4.97(\mathrm{~m}, 1 \mathrm{H})$, 4.96-4.93 (m, $1 \mathrm{H}), 4.00-3.94(\mathrm{~m}, 1 \mathrm{H}), 3.85(\mathrm{dd}, J=3.5,11.3 \mathrm{~Hz}, 1 \mathrm{H})$, $3.80-3.74(\mathrm{~m}, 1 \mathrm{H}), 3.66$ (dd, $J=3.6,11.3 \mathrm{~Hz}, 1 \mathrm{H}), 2.11-2.00(\mathrm{~m}, 2 \mathrm{H})$, 1.97-1.86 (m, $1 \mathrm{H}), 1.86-1.72$ (brs, $1 \mathrm{H}), 1.68-1.51$ (m, $2 \mathrm{H}), 1.46-1.23$ (m, $5 \mathrm{H}), 0.92(\mathrm{~s}, 9 \mathrm{H}), 0.13(\mathrm{~s}, 3 \mathrm{H}), 0.12(\mathrm{~s}, 3 \mathrm{H})$.

${ }^{13} \mathrm{C}$ NMR $\left(100 \mathrm{MHz}, \mathrm{CDCl}_{3}\right): \delta=138.8,114.2,76.0,63.7,62.7,33.6$, $33.5,28.6,28.4,26.2,25.7,18.0,-4.4,-4.6$. 
HRMS (ESI): $m / z[\mathrm{M}+\mathrm{Na}]^{+}$calcd for $\mathrm{C}_{16} \mathrm{H}_{33} \mathrm{ClO}_{2} \mathrm{Si} \mathrm{Na}{ }^{+}$: 343.1831 ; found: 343.1838 .

\section{$(3 R, 4 R, 5 S)-4$-(tert-Butyldimethylsilyloxy)-5-chloro-1-(trimethyl- silyl)dodec-11-en-1-yn-3-ol (17a)}

To a stirred solution of IBX (131.2 mg, $468 \mu \mathrm{mol})$ in DMSO $(0.5 \mathrm{~mL})$ was added alcohol $15(100 \mathrm{mg}, 312 \mu \mathrm{mol})$ in $\mathrm{CH}_{2} \mathrm{Cl}_{2}(2 \mathrm{~mL})$ at $0{ }^{\circ} \mathrm{C}$ and stirring was continued at r.t. for $4 \mathrm{~h}$. The reaction mixture was directly purified by silica column chromatography (hexane/EtOAc, 98:2) to give aldehyde 16 ( $87.4 \mathrm{mg}, 88 \%)$. A solution of $n$-BuLi $(0.2 \mathrm{~mL}, 330$ $\mu \mathrm{mol}, 1.6 \mathrm{M}$ in hexane) was added to a solution of trimethylsilyl acetylene $(0.2 \mathrm{~mL}, 1.44 \mu \mathrm{mol})$ in THF $(2.0 \mathrm{~mL})$ at $-78^{\circ} \mathrm{C}$. After $20 \mathrm{~min}$ a solution of crude aldehyde $\mathbf{1 6}(87.4 \mathrm{mg}, 275 \mu \mathrm{mol})$ in THF $(2.0 \mathrm{~mL})$ was added at $-78{ }^{\circ} \mathrm{C}$, stirring was continued for $1 \mathrm{~h}$ and the reaction was allowed to warm to $0{ }^{\circ} \mathrm{C}$ over $1 \mathrm{~h}$. The reaction mixture was quenched with sat. aq. $\mathrm{NH}_{4} \mathrm{Cl}(1 \mathrm{~mL})$ and extracted with diethyl ether $(3 \times 25 \mathrm{~mL})$. The combined organic extracts were washed with brine, dried over $\mathrm{Na}_{2} \mathrm{SO}_{4}$, filtered and concentrated in vacuo. The crude product was purified by silica column chromatography (hexane/EtOAc, 98:2) to give a mixture of alcohols $17 \mathbf{a}$ and $\mathbf{1 7 b}$ (99.4 $\mathrm{mg}, 87 \%$ ) as a colorless liquid.

\section{Major Isomer (17a)}

IR (neat): 3364, 3077, 2929, 2175, 1641, 1463, 909, $698 \mathrm{~cm}^{-1}$.

${ }^{1} \mathrm{H}$ NMR $\left(500 \mathrm{MHz}, \mathrm{CDCl}_{3}\right): \delta=5.85-5.76(\mathrm{~m}, 1 \mathrm{H}), 5.03-4.97(\mathrm{~m}, 1 \mathrm{H})$, 4.96-4.92 (m, $1 \mathrm{H}), 4.60-4.55(\mathrm{~m}, 1 \mathrm{H}), 4.14-4.09$ (m, $1 \mathrm{H}), 3.91$ (dd, $J=4.4,5.0 \mathrm{~Hz}, 1 \mathrm{H}), 2.14-2.03(\mathrm{~m}, 2 \mathrm{H}), 2.03-1.95(\mathrm{~m}, 1 \mathrm{H}), 1.68-1.54$ (m, $2 \mathrm{H}), 1.46-1.24(\mathrm{~m}, 5 \mathrm{H}), 0.93(\mathrm{~s}, 9 \mathrm{H}), 0.17$ (s, $9 \mathrm{H}), 0.16(\mathrm{~s}, 6 \mathrm{H})$.

${ }^{13} \mathrm{C}$ NMR $\left(100 \mathrm{MHz}, \mathrm{CDCl}_{3}\right): \delta=138.9,114.2,103.0,92.1,78.4,65.4$, $63.5,33.6,32.7,28.7,28.4,26.2,25.9,18.3,-0.2,-4.1,-4.2$.

\section{Minor Isomer (17b)}

${ }^{1} \mathrm{H}$ NMR $\left(500 \mathrm{MHz}, \mathrm{CDCl}_{3}\right): \delta=5.85-5.76(\mathrm{~m}, 1 \mathrm{H}), 5.03-4.97(\mathrm{~m}, 1 \mathrm{H})$, 4.96-4.92 (m, $1 \mathrm{H}), 4.60-4.55(\mathrm{~m}, 1 \mathrm{H}), 4.07-4.01(\mathrm{~m}, 1 \mathrm{H}), 3.89$ (dd, $J=3.3,5.7 \mathrm{~Hz}, 1 \mathrm{H}), 2.14-2.03$ (m, $2 \mathrm{H}), 1.94-1.86$ (m, $1 \mathrm{H}), 1.68-1.54$ (m, $2 \mathrm{H}), 1.46-1.24(\mathrm{~m}, 5 \mathrm{H}), 0.94(\mathrm{~s}, 9 \mathrm{H}), 0.17(\mathrm{~s}, 9 \mathrm{H}), 0.16(\mathrm{~s}, 6 \mathrm{H})$.

${ }^{13} \mathrm{C}$ NMR $\left(100 \mathrm{MHz}, \mathrm{CDCl}_{3}\right): \delta=138.8,114.3,104.7,90.9,79.0,63.7$, 63.4, 33.6, 33.0, 28.7, 28.4, 26.1, 25.7, 18.3, -0.2, -4.3, -4.4.

HRMS (ESI): $m / z$ [M $+\mathrm{H}]^{+}$calcd for $\mathrm{C}_{21} \mathrm{H}_{42} \mathrm{ClO}_{2} \mathrm{Si}_{2}$ : 417.2406; found: 417.2412.

(R)-1-((2R,3R)-3-(Hept-6-enyl)oxiran-2-yl)prop-2-yn-1-ol (20a)

To a stirred solution of alcohol 17a and $\mathbf{1 7 b}(20.0 \mathrm{mg}, 48.0 \mu \mathrm{mol})$ in THF at $0{ }^{\circ} \mathrm{C}, \mathrm{TBAF}(96 \mu \mathrm{L}, 96.0 \mu \mathrm{mol})$ was added. After $1 \mathrm{~h}$, the reaction mixture was concentrated and purified by silica column chromatography (hexane/EtOAc, 9:1) to give epoxyalcohols 20a and 20b (9.3 mg, $81 \%)$ as a colorless liquid.

\section{Major Isomer (20a)}

IR (neat): 3442, 3309, 2922, 2309, 1642, 1462, 1118, $910 \mathrm{~cm}^{-1}$.

${ }^{1} \mathrm{H}$ NMR $\left(400 \mathrm{MHz}, \mathrm{CDCl}_{3}\right): \delta=5.86-5.75(\mathrm{~m}, 1 \mathrm{H}), 5.03-4.97(\mathrm{~m}, 1 \mathrm{H})$, $4.96-4.92(\mathrm{~m}, 1 \mathrm{H}), 4.62-4.58(\mathrm{~m}, 1 \mathrm{H}), 3.13(\mathrm{td}, J=2.2,5.6 \mathrm{~Hz}, 1 \mathrm{H})$, 3.03 (dd, $J=2.2,3.1 \mathrm{~Hz}, 1 \mathrm{H}$ ), 2.52 (d, $J=2.3 \mathrm{~Hz}, 1 \mathrm{H}$ ), 2.39-2.22 (brs, $1 \mathrm{H}), 2.10-1.99(\mathrm{~m}, 2 \mathrm{H}), 1.64-1.56(\mathrm{~m}, 2 \mathrm{H}), 1.54-1.31(\mathrm{~m}, 6 \mathrm{H})$.

${ }^{13} \mathrm{C}$ NMR $\left(100 \mathrm{MHz}, \mathrm{CDCl}_{3}\right): \delta=138.8,114.3,80.2,74.6,60.7,59.3$, 56.0, 33.5, 31.1, $28.7(2 \mathrm{C}), 25.6$.

\section{Minor Isomer (20b)}

${ }^{1} \mathrm{H} \mathrm{NMR}\left(400 \mathrm{MHz}, \mathrm{CDCl}_{3}\right): \delta=5.86-5.75(\mathrm{~m}, 1 \mathrm{H}), 5.03-4.97(\mathrm{~m}, 1 \mathrm{H})$, 4.96-4.92 (m, $1 \mathrm{H}), 4.35-4.30(\mathrm{~m}, 1 \mathrm{H}), 3.02-2.99(\mathrm{~m}, 2 \mathrm{H}), 2.53(\mathrm{~s}$, $1 \mathrm{H}), 2.39-2.22$ (brs, $1 \mathrm{H}), 2.10-1.99(\mathrm{~m}, 2 \mathrm{H}), 1.64-1.56(\mathrm{~m}, 2 \mathrm{H})$, $1.54-1.31(\mathrm{~m}, 6 \mathrm{H})$.

${ }^{13} \mathrm{C}$ NMR $\left(100 \mathrm{MHz}, \mathrm{CDCl}_{3}\right): \delta=138.8,114.3,81.0,74.1,61.9,60.2$, 56.3, 33.5, 31.1, $28.7(2 \mathrm{C}), 25.6$.

HRMS (ESI): $m / z$ [M $+\mathrm{Na}]^{+}$calcd for $\mathrm{C}_{12} \mathrm{H}_{18} \mathrm{O}_{2} \mathrm{Na}$ : 217.1199; found: 217.1204.

(5R,6R)-5-((S)-1-Chlorooct-7-enyl)-2,2,3,3,8,8,9,9-octamethyl-6((trimethylsilyl)ethynyl)-4,7-dioxa-3,8-disiladecane (21a)

To a stirred solution of alcohols $\mathbf{1 7} \mathbf{a}$ and $\mathbf{1 7 b}(500 \mathrm{mg}, 1.20 \mathrm{mmol})$, imidazole (163 mg, $2.40 \mathrm{mmol}$ ) and DMAP (15 mg, $0.12 \mathrm{mmol}$ ) in DMF (15 mL) was added tert-butyldimethylsilyl chloride $(271 \mathrm{mg}, 1.8$ $\mathrm{mmol}$ ) at $0{ }^{\circ} \mathrm{C}$ and the mixture was allowed to stir at r.t. for $24 \mathrm{~h}$. The reaction mixture was then diluted with water, extracted with EtOAc, dried over $\mathrm{Na}_{2} \mathrm{SO}_{4}$, filtered, concentrated and purified by silica column chromatography (hexane, $100 \%$ ) to give fully protected silyl ethers 21a and 21b (586, 92\% yield) as a colorless liquid.

\section{Major Isomer (21a)}

IR (neat): 2954, 2929, 2174, 1642, 1466, 1093, 910, $699 \mathrm{~cm}^{-1}$.

${ }^{1} \mathrm{H}$ NMR $\left(400 \mathrm{MHz}, \mathrm{CDCl}_{3}\right): \delta=5.86-5.75(\mathrm{~m}, 1 \mathrm{H}), 5.03-4.96(\mathrm{~m}, 1 \mathrm{H})$, 4.95-4.90 (m, $1 \mathrm{H}), 4.44$ (d, $J=5.5 \mathrm{~Hz}, 1 \mathrm{H}), 4.15-4.09$ (m, $1 \mathrm{H}), 3.91-$ $3.87(\mathrm{~m}, 1 \mathrm{H}), 2.09-2.01(\mathrm{~m}, 2 \mathrm{H}), 1.90-1.78(\mathrm{~m}, 1 \mathrm{H}), 1.75-1.53(\mathrm{~m}$, $2 \mathrm{H}), 1.48-1.17(\mathrm{~m}, 5 \mathrm{H}), 0.92(\mathrm{~s}, 9 \mathrm{H}), 0.90(\mathrm{~s}, 9 \mathrm{H}), 0.17(\mathrm{~s}, 3 \mathrm{H}), 0.15$ (s, $9 \mathrm{H}), 0.13(\mathrm{~s}, 3 \mathrm{H}), 0.12(\mathrm{~s}, 3 \mathrm{H}), 0.11(\mathrm{~s}, 3 \mathrm{H})$.

${ }^{13} \mathrm{C}$ NMR $\left(100 \mathrm{MHz}, \mathrm{CDCl}_{3}\right): \delta=138.9,114.2,105.5,91.0,79.9,66.3$, $64.1,33.6,31.9,28.7,28.7,26.3,26.1,25.8,18.4,18.2,-0.3,-3.8,-4.3$ (2C), -4.9 .

\section{Minor Isomer (21b)}

${ }^{1} \mathrm{H} \mathrm{NMR}\left(400 \mathrm{MHz}, \mathrm{CDCl}_{3}\right): \delta=5.86-5.75(\mathrm{~m}, 1 \mathrm{H}), 5.03-4.96(\mathrm{~m}, 1 \mathrm{H})$, $4.95-4.90(\mathrm{~m}, 1 \mathrm{H}), 4.53(\mathrm{~d}, J=4.7 \mathrm{~Hz}, 1 \mathrm{H}), 4.25-4.20(\mathrm{~m}, 1 \mathrm{H}), 3.91-$ $3.87(\mathrm{~m}, 1 \mathrm{H}), 2.18-2.09(\mathrm{~m}, 2 \mathrm{H}), 1.90-1.78(\mathrm{~m}, 1 \mathrm{H}), 1.75-1.53(\mathrm{~m}$, $2 \mathrm{H}), 1.48-1.17$ (m, $5 \mathrm{H}), 0.92(\mathrm{~s}, 9 \mathrm{H}), 0.91(\mathrm{~s}, 9 \mathrm{H}), 0.17$ (s, $3 \mathrm{H}), 0.14$ (s, $9 \mathrm{H}), 0.13(\mathrm{~s}, 3 \mathrm{H}), 0.12(\mathrm{~s}, 3 \mathrm{H}), 0.11(\mathrm{~s}, 3 \mathrm{H})$.

${ }^{13} \mathrm{C}$ NMR $\left(100 \mathrm{MHz}, \mathrm{CDCl}_{3}\right): \delta=139.0,114.2,105.4,91.3,79.0,65.2$, $63.8,33.7,32.5,28.8,28.5,26.5,26.1,25.9,18.4,18.3,-0.4,-4.1,-4.1$, $-4.4,-4.8$

HRMS (ESI): $m / z[\mathrm{M}+\mathrm{H}]^{+}$calcd for $\mathrm{C}_{27} \mathrm{H}_{56} \mathrm{ClO}_{2} \mathrm{Si}_{3}$ : 531.3271 ; found: 531.3277.

(5R,6R)-5-((S)-1-Chlorooct-7-enyl)-6-ethynyl-2,2,3,3, 8,8,9,9octamethyl-4,7-dioxa-3,8-disiladecane (22a)

To a solution of silyl ethers 21a and 21b (100 mg, $188 \mu \mathrm{mol}$ ) in $\mathrm{MeOH}$ $(2 \mathrm{~mL})$, was added $\mathrm{K}_{2} \mathrm{CO}_{3}(52 \mathrm{mg}, 376 \mu \mathrm{mol})$ at $0{ }^{\circ} \mathrm{C}$. The reaction mixture was allowed to stir at r.t. for $1 \mathrm{~h}$, then diluted with water and extracted with EtOAc $(3 \times 10 \mathrm{~mL})$. The combine organic extracts were dried over $\mathrm{Na}_{2} \mathrm{SO}_{4}$, filtered and concentrated. The residue was purified by silica column chromatography (hexane, 100\%) to give 22a and 22b (78.6 mg, 91\%) as a colorless liquid.

\section{Major Isomer (22a)}

IR (neat): 3310, 3077, 2926, 2173, 1641, 1465, 1039, 909, $661 \mathrm{~cm}^{-1}$. 
${ }^{1} \mathrm{H}$ NMR $\left(400 \mathrm{MHz}, \mathrm{CDCl}_{3}\right): \delta=5.86-5.75(\mathrm{~m}, 1 \mathrm{H}), 5.03-4.96(\mathrm{~m}, 1 \mathrm{H})$, 4.96-4.91 (m, $1 \mathrm{H}), 4.58$ (dd, $J=2.0,4.4 \mathrm{~Hz}, 1 \mathrm{H}), 4.11-4.05(\mathrm{~m}, 1 \mathrm{H})$, $3.86(\mathrm{dd}, J=4.6,5.1 \mathrm{~Hz}, 1 \mathrm{H}), 2.39(\mathrm{~d}, J=2.2 \mathrm{~Hz}, 1 \mathrm{H}), 2.09-2.01(\mathrm{~m}$, $2 \mathrm{H}), 1.97-1.85$ (m, $1 \mathrm{H}), 1.74-1.55$ ( $\mathrm{m}, 2 \mathrm{H}), 1.45-1.16$ (m, $5 \mathrm{H}), 0.92$ (s, 9 H), 0.91 (s, 9 H), 0.16 (s, $3 \mathrm{H}), 0.16$ (s, $3 \mathrm{H}), 0.14$ (s, $6 \mathrm{H})$.

${ }^{13} \mathrm{C}$ NMR $\left(100 \mathrm{MHz}, \mathrm{CDCl}_{3}\right): \delta=138.9,114.2,82.9,80.0,74.3,65.8$, $63.7,33.6,32.5,28.7,28.6,26.2,26.0,25.8,18.4,18.2,-3.8,-4.3,-4.4$, -5.0 .

\section{Minor Isomer (22b)}

${ }^{1} \mathrm{H} \mathrm{NMR}\left(400 \mathrm{MHz}, \mathrm{CDCl}_{3}\right): \delta=5.86-5.75(\mathrm{~m}, 1 \mathrm{H}), 5.03-4.96(\mathrm{~m}, 1 \mathrm{H})$, $4.96-4.91(\mathrm{~m}, 1 \mathrm{H}), 4.54(\mathrm{dd}, J=2.3,4.7 \mathrm{~Hz}, 1 \mathrm{H}), 4.26-4.21(\mathrm{~m}, 1 \mathrm{H})$, 3.91 (dd, $J=3.9,4.6 \mathrm{~Hz}, 1 \mathrm{H}), 2.39(\mathrm{~d}, J=2.2 \mathrm{~Hz}, 1 \mathrm{H}), 2.09-2.01(\mathrm{~m}$, $2 \mathrm{H}), 1.97-1.85(\mathrm{~m}, 1 \mathrm{H}), 1.74-1.55(\mathrm{~m}, 2 \mathrm{H}), 1.45-1.16(\mathrm{~m}, 5 \mathrm{H}), 0.92$ (s, $9 \mathrm{H}), 0.91$ (s, $9 \mathrm{H}), 0.16$ (s, $3 \mathrm{H}), 0.16$ (s, $3 \mathrm{H}), 0.14$ (s, $6 \mathrm{H})$.

${ }^{13} \mathrm{C}$ NMR $\left(100 \mathrm{MHz}, \mathrm{CDCl}_{3}\right): \delta=139.0,114.1,83.3,79.0,74.5,64.7$, 63.4, 33.6, 32.5, 28.7, 28.4, 26.4, 25.9, 25.7, 18.3, 18.1, -4.1, -4.2, -4.5, -5.0 .

HRMS (ESI): $m / z[\mathrm{M}+\mathrm{H}]^{+}$calcd for $\mathrm{C}_{24} \mathrm{H}_{48} \mathrm{ClO}_{2} \mathrm{Si}_{2}{ }^{+}:$459.2876; found: 459.2874 .

\section{(3R,4R,5S)-5-Chlorododec-11-en-1-yne-3,4-diol (19a)}

PTSA ( $38 \mathrm{mg}, 21.8 \mu \mathrm{mol}$ ) was added to a stirred solution of di-TBS ethers 22a and 22b (50 mg, $109 \mu \mathrm{mol})$ in $\mathrm{MeOH}$ at $0{ }^{\circ} \mathrm{C}$ and stirring was continued for $2 \mathrm{~h}$. Solid $\mathrm{NaHCO}_{3}$ was added at $0{ }^{\circ} \mathrm{C}$ to quench the reaction and the mixture was filtered and concentrated. The crude residue containing diols $\mathbf{1 9 a}$ and $\mathbf{1 9 b}$ was subjected to silica column chromatography (hexane/EtOAc, 7:3) to give diol 19a (18.2 mg, 72.8\%) and 19b (4.0 mg, 16.1\%) [total yield: $22.3 \mathrm{mg}(89 \%)$ ] as colorless liquids.

Alternatively, a mixture of TBAF ( $293 \mu \mathrm{mol}, 1 \mathrm{M}$ in THF) and acetic acid ( $293 \mu \mathrm{mol}, 1 \mathrm{M}$ in THF) was added to a solution of alcohols 17a and 17b $(61 \mathrm{mg}, 146.6 \mu \mathrm{mol})$ in THF $(1 \mathrm{~mL})$ at $0{ }^{\circ} \mathrm{C}$ and the mixture allowed to stir for $1 \mathrm{~h}$ at the same temperature. Removal of the THF and acetic acid in vacuo and purification by silica column chromatography (hexane/EtOAc, 7:3) gave diol 19a (20.4 mg, 60.5\%) and diol 19b (4.5 mg, 13.4\%) as colorless liquids (total yield: $24.9 \mathrm{mg}, 74 \%$ ).

\section{Major Compound (19a)}

$[\alpha]_{D}{ }^{20}-18.8\left(c \quad 1.1, \mathrm{CHCl}_{3}\right)$.

IR (neat): 3378, 3296, 3076, 2925, 2117, 1640, 1436, 1041, 910, 642 $\mathrm{cm}^{-1}$.

${ }^{1} \mathrm{H}$ NMR $\left(300 \mathrm{MHz}, \mathrm{CDCl}_{3}\right): \delta=5.86-5.76(\mathrm{~m}, 1 \mathrm{H}), 5.05-4.90(\mathrm{~m}, 2 \mathrm{H})$, 4.89-4.84 (m, $1 \mathrm{H}), 3.93(\mathrm{td}, J=2.4,9.1 \mathrm{~Hz}, 1 \mathrm{H}), 3.82-3.76(\mathrm{~m}, 1 \mathrm{H})$, 3.42-2.82 (brs, $2 \mathrm{H}), 2.56$ (d, J = 2.1 Hz, $1 \mathrm{H}), 2.14-2.04$ (m, $3 \mathrm{H}), 1.75-$ 1.58 (m, $2 \mathrm{H}), 1.49-1.27(\mathrm{~m}, 5 \mathrm{H})$.

${ }^{13} \mathrm{C}$ NMR (100 MHz, $\mathrm{CDCl}_{3}$ ): $\delta=138.8,114.3,80.2,76.3,75.6,64.0$, 61.9, 33.5 (2C), 28.6, 28.5, 25.5.

HRMS (ESI): $m / z[\mathrm{M}+\mathrm{H}]^{+}$calcd for $\mathrm{C}_{12} \mathrm{H}_{20} \mathrm{ClO}_{2}: 231.1146$; found: 231.1152.

\section{Minor Compound (19b)}

$[\alpha]_{D}{ }^{20}-11.0\left(\mathrm{c} 0.5, \mathrm{CHCl}_{3}\right)$.

IR (neat): 3396, 3297, 3076, 2923, 2118, 1640, 1436, 1037, 910, 670 $\mathrm{cm}^{-1}$.
${ }^{1} \mathrm{H}$ NMR $\left(400 \mathrm{MHz}, \mathrm{CDCl}_{3}\right): \delta=5.85-5.76(\mathrm{~m}, 1 \mathrm{H}), 5.03-4.97(\mathrm{~m}, 1 \mathrm{H})$, 4.97-4.91 (m, $1 \mathrm{H}), 4.75-4.70(\mathrm{~m}, 1 \mathrm{H}), 4.12-4.07(\mathrm{~m}, 1 \mathrm{H}), 3.82-3.74$ (m, $1 \mathrm{H}), 3.03-2.88$ (brs, $2 \mathrm{H}), 2.55(\mathrm{~d}, J=2.2 \mathrm{~Hz}, 1 \mathrm{H}), 2.09-2.02(\mathrm{~m}$, $2 \mathrm{H}), 1.99-1.91$ (m, $1 \mathrm{H}), 1.80-1.69$ ( $\mathrm{m}, 1 \mathrm{H}), 1.67-1.57$ (m, $1 \mathrm{H}), 1.49-$ $1.27(\mathrm{~m}, 5 \mathrm{H})$.

${ }^{13} \mathrm{C}$ NMR $\left(100 \mathrm{MHz}, \mathrm{CDCl}_{3}\right): \delta=138.8,114.3,81.9,77.3,74.8,62.5$, $61.9,33.5,32.8,28.6,28.4,25.8$.

HRMS (ESI): $m / z[M+H]^{+}$calcd for $\mathrm{C}_{12} \mathrm{H}_{20} \mathrm{ClO}_{2}: 231.1146$; found: 231.1155.

\section{(8R,9R,10S)-10-Chloroheptadeca-16-en-4,6-diyne-8,9-diol (4)}

$\mathrm{CuCl}(1 \mathrm{mg}, 10 \mu \mathrm{mol})$ was added to a $30 \% n-\mathrm{BuNH}_{2}$ solution at r.t., leading to a blue solution. To discharge the blue color a few crystals of hydroxylamine hydrochloride were added. Alkyne 19a $(10 \mathrm{mg}, 43.4$ $\mu \mathrm{mol})$ in diethyl ether $(1 \mathrm{~mL})$ was then added, the mixture was cooled to $0{ }^{\circ} \mathrm{C}$ and 1 -iodopent-1-yne $(10 \mathrm{mg}, 52 \mu \mathrm{mol})$ in diethyl ether $(0.5$ $\mathrm{mL}$ ) was added. The reaction mixture was allowed to warm to r.t. and stirring was continued for $30 \mathrm{~min}$. It was necessary to add hydroxylamine hydrochloride crystals at appropriate intervals during the reaction to prevent the solution from turning blue or green. The reaction mixture was extracted with diethyl ether $(3 \times 10 \mathrm{~mL})$, the combined extracts were dried over $\mathrm{Na}_{2} \mathrm{SO}_{4}$, filtered and concentrated under reduced pressure. The crude product was purified by silica column chromatography (hexane/EtOAc, 9:1) to give ciryneol C 4.

Yield: $10.4 \mathrm{mg}(81 \%) ;[\alpha]_{\mathrm{D}}{ }^{20}+1.3\left(c \mathrm{0.9}, \mathrm{CHCl}_{3}\right)\left\{\right.$ lit. $^{4}$ ciryneol C, $[\alpha]_{\mathrm{D}}{ }^{23}$ +20.7 ( c 1.0, $\left.\mathrm{CHCl}_{3}\right)$ ).

IR (neat): 3308, 3289, 3031, 2925, 2254, 1641, 1460, 1053, 910, 649 $\mathrm{cm}^{-1}$.

${ }^{1} \mathrm{H}$ NMR $\left(500 \mathrm{MHz}, \mathrm{CDCl}_{3}\right): \delta=5.81(\mathrm{~m}, 1 \mathrm{H}, \mathrm{H}-2), 5.00(\mathrm{~m}, 1 \mathrm{H}, \mathrm{H}-1)$, 4.95 (m, $\left.1 \mathrm{H}, \mathrm{H}-1^{\prime}\right), 4.88$ (m, $\left.1 \mathrm{H}, \mathrm{H}-10\right), 3.92$ (m, $\left.1 \mathrm{H}, \mathrm{H}-8\right), 3.77$ (m, $1 \mathrm{H}, \mathrm{H}-9), 2.93$ (m, $1 \mathrm{H}, \mathrm{H} 9-\mathrm{OH}), 2.73$ (m, $1 \mathrm{H}, \mathrm{H} 10-\mathrm{OH}), 2.26$ (m, $2 \mathrm{H}$, H-15, H-15'), 2.06 (m, 3 H, H-3, H-3', H-6 ), 1.71 (m, 2 H, H-7, H-7'), 1.62 (m, 3 H, H-5, H-5', H-6'), 1.57 ( m, 2 H, H-16, H-16' ), 1.41 (m, 2 H, $\left.\mathrm{H}-4, \mathrm{H}-4^{\prime}\right), 0.99$ (t, $\left.3 \mathrm{H}, J=7.4 \mathrm{~Hz}, \mathrm{H}-17\right)$.

${ }^{13} \mathrm{C}$ NMR $\left(100 \mathrm{MHz}, \mathrm{CDCl}_{3}\right): \delta=138.9,114.3,82.1,76.6,72.4,71.6$, $64.8,64.2,62.0,33.6,33.5,28.6,28.5,25.5,21.5,21.1,13.4$.

HRMS (ESI): $m / z$ [M + Na] ${ }^{+}$calcd for $\mathrm{C}_{17} \mathrm{H}_{25} \mathrm{ClO}_{2} \mathrm{Na}^{+}: 319.1435$; found: 319.1421.

The assignment of protons was based on 2D NMR (gDQFCOSY, and NOESY) experiments. The presence of characteristic NOE correlations between $\mathrm{C}_{8} \mathrm{H} / \mathrm{C}_{10} \mathrm{H}, \mathrm{C}_{8} \mathrm{H} / \alpha-\mathrm{OH}, \mathrm{C}_{9} \mathrm{H} / \mathrm{C}_{7} \mathrm{H}, \mathrm{C}_{10} \mathrm{H} / \beta-\mathrm{OH}, \mathrm{C}_{8} \mathrm{H} / \mathrm{C}_{6} \mathrm{H}$, confirmed the assigned structure (see the Supporting Information).

\section{Funding Information}

A.S. thanks UGC, New Delhi, India for the award of a Fellowship. The authors thank CSIR, New Delhi, India for financial support and GAP 0623 Ministry of AYUSH.

\section{Supporting Information}

Supporting information for this article is available online at https://doi.org/10.1055/s-0037-1611876. 


\section{References}

(1) Myneni, S. C. B. Science 2002, 295, 1039.

(2) Engvild, K. C. Phytochemistry 1986, 25, 781.

(3) Yoon, M.-Y.; Choi, G. J.; Choi, Y. H.; Jang, K. S.; Cha, B.; Kim, J. C. Industrial Crops and Products 2011, 34, 882; and references therein.

(4) Takaishi, Y.; Okuyama, T.; Masuda, A.; Nakano, K.; Murakami, K.; Tomimastu, T. Phytochemistry 1990, 29, 3849.

(5) Lai, W.-C.; Wu, Y.-C.; Danko, B.; Cheng, Y.-B.; Hsieh, T.-J.; Hsieh, C.-T.; Tsai, Y.-C.; El-Shazly, M.; Martins, A.; Hohmann, J.; Hunyadi, A.; Chang, F.-R. J. Nat. Prod. 2014, 77, 1624.

(6) Castejon, P.; Moyano, A.; Pericas, M. A.; Riera, A. Synth. Commun. 1994, 24, 1231.

(7) Watanbe, H.; Watanable, H.; Kitahra, T. Tetrahedron Lett. 1998, $39,8313$.
(8) Yoshimitsu, T.; Fukumoto, N.; Nakatani, R.; Kojima, N.; Tanaka, T. J. Org. Chem. 2010, 75, 5425.

(9) Wang, C.; Yamamoto, H. Org. Lett. 2014, 16, 5937.

(10) Sharada, A.; Rao, S. L. K.; Yadav, S. J.; Rao, P. T.; Nagaiah, K. Synthesis 2017, 47, 2483.

(11) Ramulu, U.; Ramesh, D.; Reddy, S. P.; Rajaram, S.; Babu, K. S. Tetrahedron: Asymmetry 2014, 25, 1409.

(12) Mori, K. Tetrahedron 2012, 68, 1936.

(13) (a) Burova, S. A.; McDonald, F. E. J. Am. Chem. Soc. 2002, 124, 8188. (b) Rao, K. N.; Kanakaraju, M.; Kunwar, C. A.; Ghosh, S. Org. Lett. 2016, 18, 4092.

(14) Wu, C.-J.; Madhushaw, R. J.; Liu, R.-S. J. Org. Chem. 2003, 68, 7889.

(15) Vedrenne, E.; Royer, F.; Oble, J.; El Kaïm, L.; Grimaud, L. Synlett 2005, 2379.

(16) Cadiot, P.; Chodkiewicz, W. In Chemistry of Acetylenes; Viehe, H. G., Ed.; Marcel Dekker: New York, 1969, 597-647. 